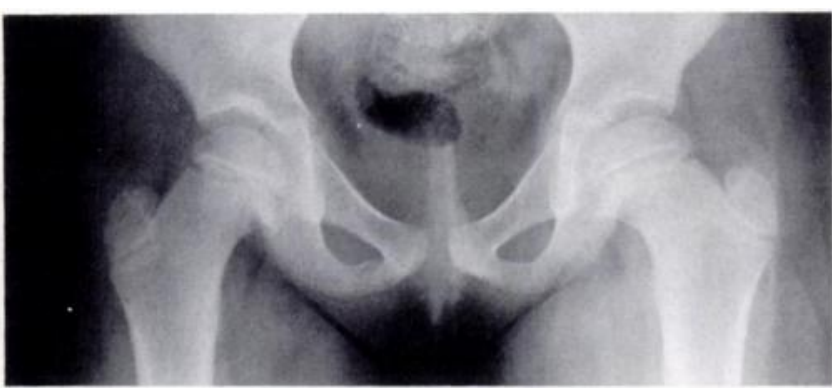

Fig. 3a

Fröhlich-type body and anatomical variations such as excess retroversion.

In contrast, bilateral cases are most common during treatment for hypothalamo-pituitary axis failure, during which hormone replacement can result in a rapid gain in height and weight. Another cause is hyperparathyroidism, either primary or secondary to chronic renal failure.

'In-situ' pinning has been used for a mild or moderate slip but in this young age group complications such as growth arrest are numerous. Leg-length discrepancy is often less than should theoretically occur; in some cases the contralateral physis also undergoes premature fusion, as a result of the underlying constitutional disorder or from asymptomatic slip. Chondrolysis is another possible complication of nailing, and avascular necrosis may follow any type of manipulative reduction.

Severe slips have a poorer long-term prognosis for arthritic degeneration but the theoretical advantages of improving the biomechanics are outweighed by the complications of osteotomy in this young age group.

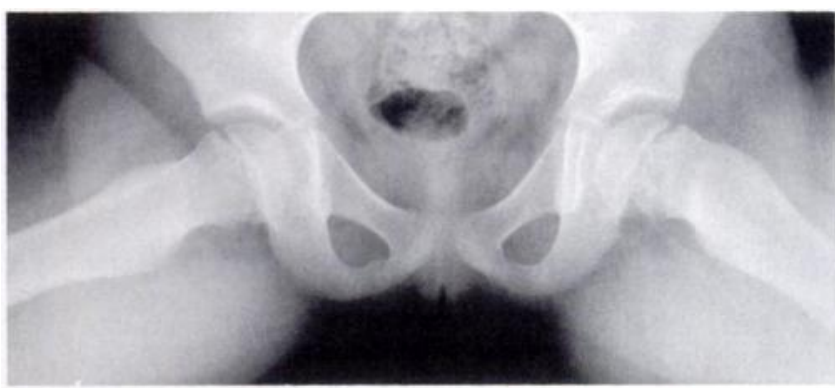

Fig. 3b

Spica-cast treatment has not been associated with chondrolysis in this age group, and has been shown to stabilise the slip and leave excellent potential for remodelling (Clarke and Harrison 1986).

No benefits in any form have been received or will be received from a commercial party related directly or indirectly to the subject of this article.

\section{REFERENCES}

Barrett IR. Slipped capital femoral epiphysis following radiotherapy. $J$ Pediatr Orthop 1985; 5:268-73.

Betz RR, Steel HH, Emper WD, Huss GK, Clancy M. Treatment of slipped capital femoral epiphysis: spica-cast immobilization. $J$ Bone Joint Surg [Am] 1990; 72-A:587-600.

Clarke NMP, Harrison MHM. Slipped upper femoral epiphysis: a potential for spontaneous recovery. J Bone Joint Surg /Br] 1986; 68B:541-4.

Cohen MS, Gelberman RH, Grifín PP, et al. Slipped capital femoral epiphysis: assessment of epiphyseal displacement and angulation. $J$ Pediatr Orthop 1986; 6:259-64.

Waldenström H. Om epifysglidningen I höftleden. Stockholm, 1939:24

Wilson PD. The treatment of slipping of the upper femoral epiphysis with minimal displacement. J Bone Joint Surg 1938; 20:379-99.

\title{
TIBIAL CAST WEDGING: A SIMPLE AND EFFECTIVE TECHNIQUE
}

\section{P. A. GREGSON, P. B. M. THOMAS}

Charnley (1950) considered that "contrary to popular opinion, the operative treatment of fractures is much simpler than is the non-operative" and that "the manipulative treatment of fractures can be resolved into something of a science'". With recent advances in external fixation and closed nailing, many tibial fractures that were traditionally well managed in casts are now being treated

P. A. Gregson, FRCS, Registrar in Orthopaedics Hereford General Hospital, Nelson Street, Hereford HR1 2NZ, UK.

P. B. M. Thomas, FRCS, FRCS Ed, Senior Lecturer in Orthopaedics Department of Postgraduate Medicine, North Staffordshire Royal Infirmary, Thornburrow Drive, Stoke-on-Trent, Staffordshire ST4 7QB, UK.

Correspondence to Mr P. B. M. Thomas.

(C)1994 British Editorial Society of Bone and Joint Surgery 0301-620X/94/3R03 \$2.00

J Bone Joint Surg [Br] 1994; 76-B:496-7.

Received 9 July 1993; Accepted 25 August 1993 by surgical fixation (Apley and Rowley 1992) and the failure to achieve an acceptable position in a cast is rectified by operation rather than by correction within the plaster.

We describe a technique for the accurate wedging of tibial casts. Similar methods were well known in the past and our modification has proved to be simple, effective, and reliable over a number of years. We present one illustrative case.

Technique. Ideally, the procedure is performed three weeks after injury when the fracture is mobile but 'sticky' and correction is almost painless

The method sounds complex, but can be done quickly using only a ruler and marker pen. No measurement of angles is necessary (Fig. 1).

1) On the anteroposterior radiograph draw lines along the long axes of the proximal and distal fragments of the tibia. 


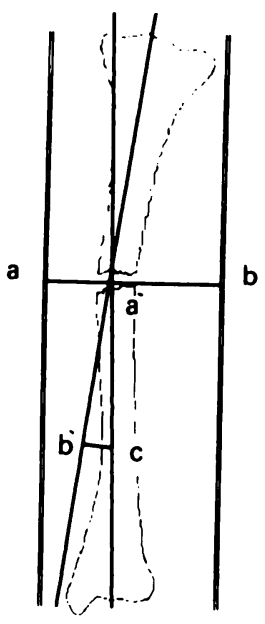

Fig. 1

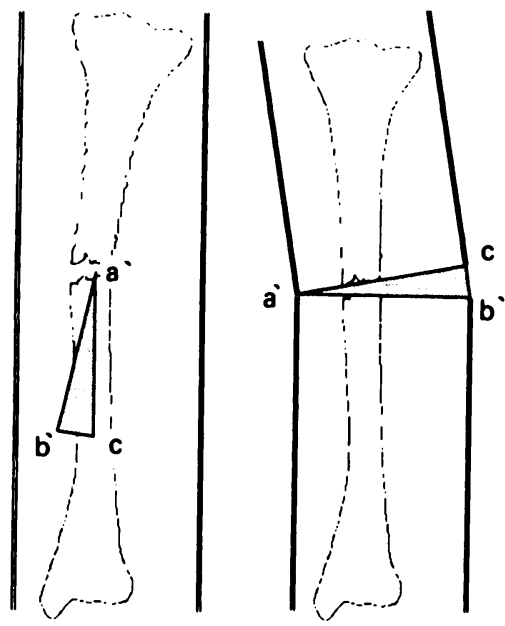

Fig. 2a

Fig. $2 b$
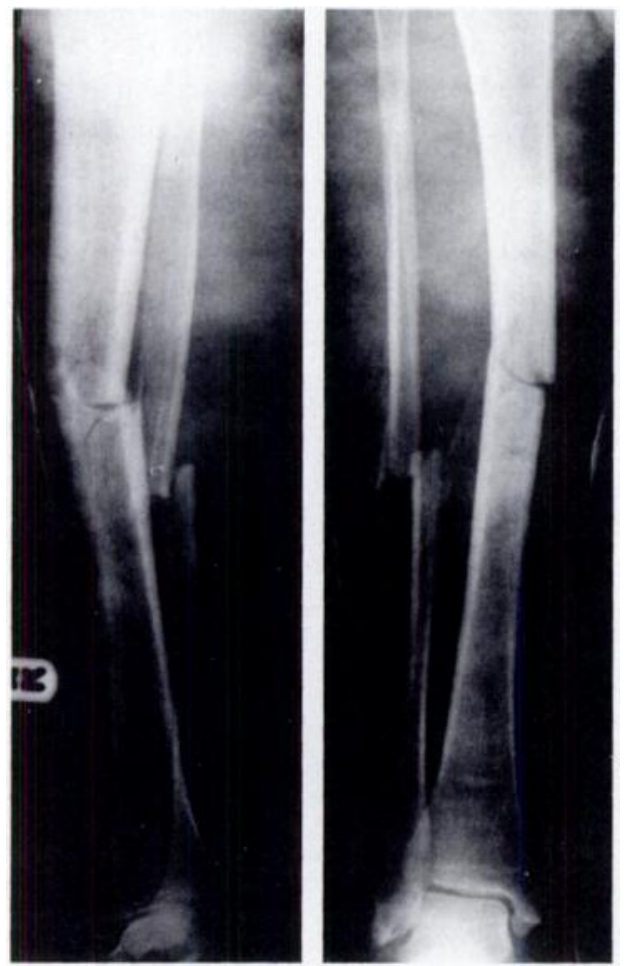

circumference intact to act as a hinge opposite the midway point between the positions of the two wedges.

6) Cut pieces of cork to the size required for each wedge, and apply sufficient force to the plaster to open the gap and correct the angulation in both planes.

7) Insert the wedges to hold the reduction.

8) After check radiographs to ensure satisfactory correction, pack wool into the gap and complete the plaster around the wedges.

Accurate reduction is obtained when the triangle created by the deformity (Fig. 2a) is reproduced by the correction (Fig. 2b). It must be emphasised that hinging occurs at the cast rather than at the fracture.

One illustrative case is shown in Figure 3, with radiographs before (a) and after wedging (b). We have seen no complications from this method of treatment, and reduction has always been maintained.
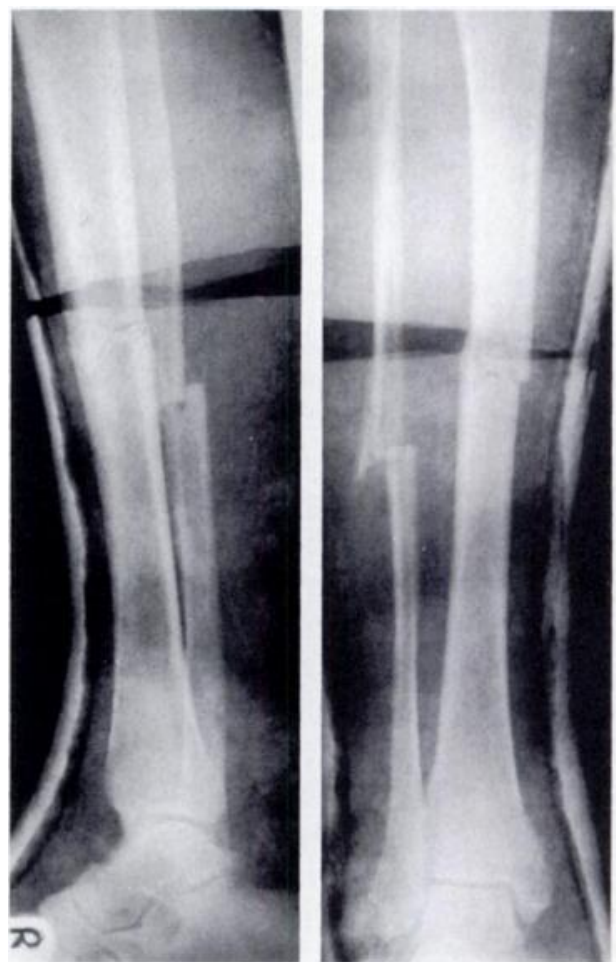

Fig. 3

2) Measure the diameter of the cast ab at the level of the fracture, and mark this distance $a^{\prime} b^{\prime}$ on the 'ideal' line extended down from the end of the proximal fragment, starting at the intersection of the two lines.

3) From $b^{\prime}$ draw a line to meet the axis of the distal fragment creating an isosceles triangle with equal sides $a^{\prime} b^{\prime}$ and $a^{\prime} c$. Measure the distance $b^{\prime} c$, which is the thickness of the required wedge in this plane.

4) Repeat the same procedure on the lateral radiograph to obtain a measurement for the wedge required in this plane.

5) Draw a line around the cast at the level of the fracture, mark the position of the wedges and then cut around the line with a plaster saw, leaving a quarter of the
Discussion. This technique is easy to learn, simple and effective. Cast wedging has allowed the outpatient management of many patients who might otherwise have needed admission for manipulation under anaesthesia or operative reduction and fixation.

No benefits in any form have been received or will be received from a commercial party related directly or indirectly to the subject of this article.

\section{REFERENCES}

Apley AG, Rowley DI. Editorial: Fixation is fun. J Bone Joint Surg [Br] 1992; 74-B:485-6.

Charnley J. The closed treatment of common fractures. Preface to the first edition. London: E \& S Livingstone Ltd, 1950. 